\title{
Effect of early treatment with propranolol on left ventricular function four weeks after myocardial infarction
}

\author{
MICHAEL A BROWN, ROBIN M NORRIS, PETER F BARNABY, \\ GRAYSON G GEARY, PETER W BRANDT \\ From the Coronary Care Unit and Department of Cardiac Radiology, Green Lane Hospital, Auckland, New \\ Zealand
}

SUMMARY Left ventricular function and exercise capacity were assessed in 79 patients randomised to receive intravenous and oral propranolol $(n=44)$ or conventional therapy $(n=35)$ within four hours of onset of their first myocardial infarction. Cineangiocardiography and exercise testing were performed four weeks after infarction to allow for maximum recovery of myocardial function. Left ventriculography showed no improvement in ejection fraction or preservation of regional contractile function in patients treated with propranolol compared with controls. A trend towards smaller end diastolic volumes was seen in the propranolol group (mean (SD) 151(42) ml) compared with controls $(167(42) \mathrm{ml})$. Exercise duration and frequency of angina were not significantly different in the two groups. It is concluded that limitation of infarct size by propranolol does not lead to a significant improvement in ventricular systolic function, although left ventricular dilatation may be reduced. These findings are consistent with the known effect of early intravenous beta blockade which limits infarct size by preservation of subepicardial myocardium.

Infarct size, reflected by the degree of left ventricular dysfunction, is accepted as the major predictor of cardiac mortality after myocardial infarction. Limitation of infarct size with propranolol was first shown experimentally by Maroko and colleagues in $1971^{1}$ and indirect indices of infarct size have been used in man to demonstrate a beneficial effect of beta blockers. $^{2-4}$ The hypothesis, however, that limitation of infarct size would lead to improvement in ventricular function has been poorly evaluated in man. Pathophysiological observations suggest that treatment would be most effective if it were started earlywithin four hours of the onset of infarction. ${ }^{5}$ We have analysed late ventricular function and exercise capacity in a group of patients randomised to receive intravenous propranolol or conventional therapy within four hours of onset of their first infarction.

\section{Patients and methods}

Between May 1981 and March 1984 a randomised trial of intravenous propranolol versus no inter-

Requests for reprints to Dr RM Norris, Coronary Care Unit, Green Lane Hospital, Auckland 3, New Zealand.

Accepted for publication 10 June 1985 vention was conducted in 735 patients with suspected myocardial infarction. ${ }^{6}$ Entry to the trial was required within four hours of the onset of chest pain, which was of at least 30 minutes' duration and judged to be due to myocardial ischaemia. Exclusion criteria were asthma, significant cardiac failure, systolic blood pressure below $110 \mathrm{~mm} \mathrm{Hg}$, or heart rate below 60 beats per minute. Intravenous propranolol $(0.1 \mathrm{mg} / \mathrm{kg})$ was followed by an oral dose of up to 320 mg given over the next 27 hours, in divided doses of $40 \mathrm{mg}$. Individual doses were omitted when there was bradycardia of less than 50 beats per min or systolic blood pressure below $100 \mathrm{~mm} \mathrm{Hg}$, and treatment was discontinued if there was cardiac failure or atrioventricular block of greater than first degree. In the propranolol group there was a significant reduction in the incidence of ventricular fibrillation within the first 48 hours after infarction. ${ }^{6}$ There was no reduction in mortality and the frequency of heart block or use of diuretic therapy was similar in both groups.

Over the same period a subgroup of all male patients less than 60 years of age with no previous myocardial infarction who entered the trial from one hospital with cardiac catheterisation facilities was selected prospectively for investigation four weeks after their initial hospital admission. Patients who 
had had cardiac surgery were excluded. All patients selected had electrocardiographic evidence of abnormal $Q$ waves ( $Q$ wave infarction) or serial ST segment and $T$ wave changs without abnormal $Q$ waves (non- $Q$ wave infarction) and raised creatine kinase. The study was approved by the hospital ethics committee and all patients gave informed consent.

Patients were readmitted to hospital for exercise testing and angiocardiography four weeks after infarction. Exercise testing was performed on a treadmill at a constant speed of 2.5 miles $(4 \mathrm{~km})$ per hour at gradients of 0,5 , and 10 degrees for three minutes each and 15 degrees for six minutes. Exercise was stopped if significant angina or dyspnoea developed, and a 12 lead electrocardiogram was recorded immediately after exercise. Flat or downsloping ST segment depression of $1 \mathrm{~mm}$ was required as evidence for myocardial ischaemia.

Single plane left ventriculography and coronary angiography were carried out by the Judkins technique, left ventriculography being performed in the $40^{\circ}$ right anterior oblique position. Left ventriculograms were recorded on $35 \mathrm{~mm}$ cine film at 50 frames per second. Cine film images were projected and the end diastolic and end systolic outlines were hand traced and subsequently digitised. Extrasystoles and post extrasystolic beats were excluded from the analysis. Ventricular volumes and ejection fraction were calculated by Simpson's rule with correction factors based. on a comparison of radioopaque left ventricular casts from postmortem hearts, ${ }^{7}$ and the indices were calculated according to body surface area. Experienced cardiac radiologists who were unaware of the randomisation group, assessed left ventricular contractility by subjective analysis of the movement of the cardiac silhouette in the right anterior oblique projection which was divided into five segments. Each segment was scored for contractility: normal 0 , hypokinetic 1 , akinetic 2 , and dyskinetic 3 , and the number from each segment was summed to give a contractility score (range 0 to 15). ${ }^{8}$ Calculation of the coronary arteriographic score $^{9}$ was based both on the severity of the individual stenotic lesions and on the amount of left ventricular myocardium supplied by each involved vessel. This arteriographic score was expressed by a number in the range of $0-15 ; \leqslant 5$ was approximately equivalent to one vessel disease; 5-10 to two vessel disease; and $>10$ to three vessel disease.

Data on clinical features together with results of angiocardiography and exercise testing were stored on a PDP11 minicomputer. Clinical and electrocardiographic variables were compared by means of the $\chi^{2}$ test. No distribution of continuous variables was assumed, and accordingly comparison between groups was made by means of the non-parametric
Mann-Whitney $U$ test with a two-tailed p. value. Results are expressed as mean (SD).

\section{Results}

\section{Study group}

Of the 735 patients admitted to the randomised trial, 407 developed myocardial infarction. Of these, 94 patients were enrolled at one hospital and met our inclusion criteria for subsequent investigation of sex (male), age less than 60 years, and no previous infarction. Fifty of these patients received intravenous propranolol, and 44 conventional treatment. Eight patients died in hospital or before investigation (three propranolol, five control). Patients with serious unrelated medical disorders were not regarded as suitable for investigation (three propranolol, three control) and one patient in the control group refused investigation. The clinical characteristics of the remaining patients, 44 in the propranolol and 35 in the control group, are listed in Table 1 . Treated patients were older than controls (mean 52 vs 47 years, $p=0.004$ ), but the frequency of previous angina was similar in the two groups. Four patients in the control group and eight in the propranolol group were receiving beta blocker therapy before their infarction. Baseline heart rate and blood pressure before entry to the trial were similar in both groups. The mean time of administration of the first intravenous dose of propranolol was $2 \cdot 8$ hours from the onset of chest pain and was less than 4 hours in all patients. Heart rate fell from a mean of 79 beats per minute to 68 beats per minute within 10 minutes of administration of intravenous propranolol; this resembles the change observed in our previously reported trials in which a reduction of creatine kinase

Table 1 Clinical and electrocardiographic data on propranolol and control groups

\begin{tabular}{|c|c|c|}
\hline & $\begin{array}{l}\text { Propranolol } \\
(n=44)\end{array}$ & $\begin{array}{l}\text { Control } \\
(n=35)\end{array}$ \\
\hline $\begin{array}{l}\text { Age in years (mean and range) } \\
\text { Previous angina } 3 \text { months' }\end{array}$ & $52(35-59)$ & $47(32-59)$ \\
\hline $\begin{array}{l}\text { duration } \\
\text { Beta blocker therapy before entry } \\
\text { Baseline mean heart rate (SD) } \\
\text { Baseline mean blood pressure }\end{array}$ & $\begin{array}{l}12(27 \%) \\
8(18 \%) \\
79(15)\end{array}$ & $\begin{array}{l}7(20 \%) \\
4(11 \%) \\
79(19)\end{array}$ \\
\hline $\begin{array}{l}\text { (mm Hg) } \\
\text { Electrocardiogram on entry: }\end{array}$ & $150 / 95$ & $153 / 96$ \\
\hline $\begin{array}{l}\text { Normal } \\
\text { Abnormal } Q \text { waves } \\
\text { ST segment elevation } \\
\text { Primary ST depression } \\
\text { T wave inversion only }\end{array}$ & $\begin{array}{c}1(2 \%) \\
13(30 \%) \\
36(82 \%) \\
3(7 \%) \\
3(7 \%)\end{array}$ & $\begin{array}{l}3(9 \%) \\
10(29 \%) \\
22(63 \%) \\
5(14 \%) \\
5(14 \%)\end{array}$ \\
\hline $\begin{array}{l}\text { Time from onset of pain to trial } \\
\text { entry (h(SD)) }\end{array}$ & $2 \cdot 8(0.7)$ & $2 \cdot 4(1 \cdot 0)$ \\
\hline $\begin{array}{l}\text { Final diagnosis: } \\
\text { Anterior } Q \text {.wave infarction } \\
\text { Inferior } Q \text { wave infarction } \\
\text { Non- } Q \text { wave infarction }\end{array}$ & $\begin{array}{r}23(52 \%) \\
13(30 \%) \\
8(18 \%)\end{array}$ & $\begin{array}{r}15(43 \%) \\
12(34 \%) \\
8(23 \%)\end{array}$ \\
\hline
\end{tabular}




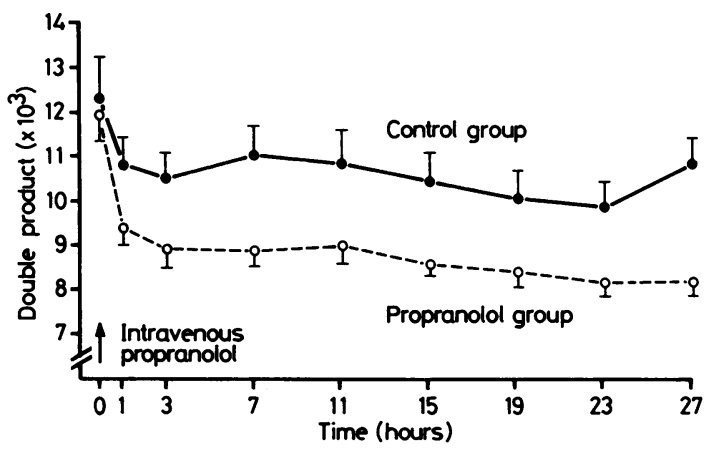

Fig. 1 Reduction of double product (systolic blood pressure $\times$ heart rate) after intravenous and oral propranolol in the propranolol group compared with the control group. Means and standard errors are shown.

was shown in the propranolol group. ${ }^{210}$ The lower double product (systolic blood pressure $x$ heart rate) achieved in the propranolol group is shown in Fig. 1. ST segment elevation was more common in the propranolol group on entry $(82 \%$ vs $63 \%$, $\mathrm{p}=\mathbf{0} \cdot \mathbf{1}$ ), and on discharge from hospital this group showed a higher proportion of completed anterior $\mathbf{Q}$ wave infarcts than did the control group $(52 \%$ vs $43 \%, p=N S$ ).

\section{Exercise test}

The protocol was completed by 24 and 22 patients of the control and propranolol groups respectively ( $p$, not significant), while the mean exercise duration of patients not completing the protocol was 9(3) minutes in both groups. Similar numbers of patients in the control and propranolol groups developed angina during the exercise test (17 vs 15 patients) and ischaemic electrocardiographic changes after exercise ( 13 vs 14 patients). The peak mean heart rate was 141(26) beats per minute in the control group compared with $137(25)$ beats per minute in the propranolol group ( $p$, not significant). Seven patients in the control group and nine in the propranolol group were on beta blockers at the time of exercise testing.

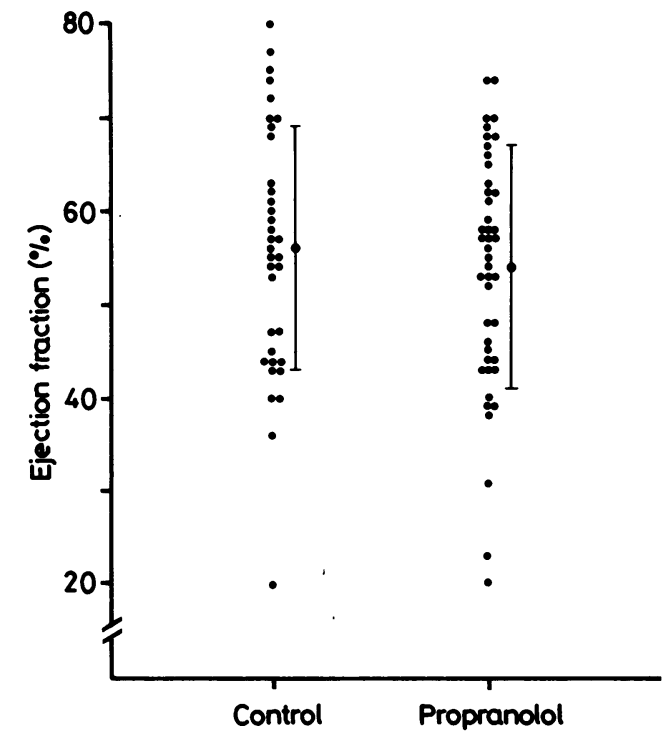

Fig. 2 Ejection fraction of individual patients 4 weeks after their first myocardial infarction in control $(n=35)$ and propranolol $(n=44)$ groups.

\section{Cineangiocardiography}

Group values for end diastolic volume, end systolic volume, ejection fraction, and contractility scores are shown in Table 2, while the ejection fractions and end diastolic volumes of individual patients are shown in Figs. 2 and 3. There was no significant difference for any of these variables between the propranolol and control groups. This result was unchanged after correction of ventricular volumes for body surface area. There was a trend towards smaller end diastolic volumes in the propranolol group (151 (42) $\mathrm{ml}$ vs $167(42) \mathrm{ml}, \mathrm{p}=0.08$ ). In the total group of patients the contractility score correlated well with the ejection fraction $(r=0.78)$.

Subgroup analysis based on the position and extent of infarction (Table 2) showed that all propranolol subgroups had lower mean end diastolic volumes than the control subgroups, although this

Table 2 Indices of left ventricular function for propranolol and control groups

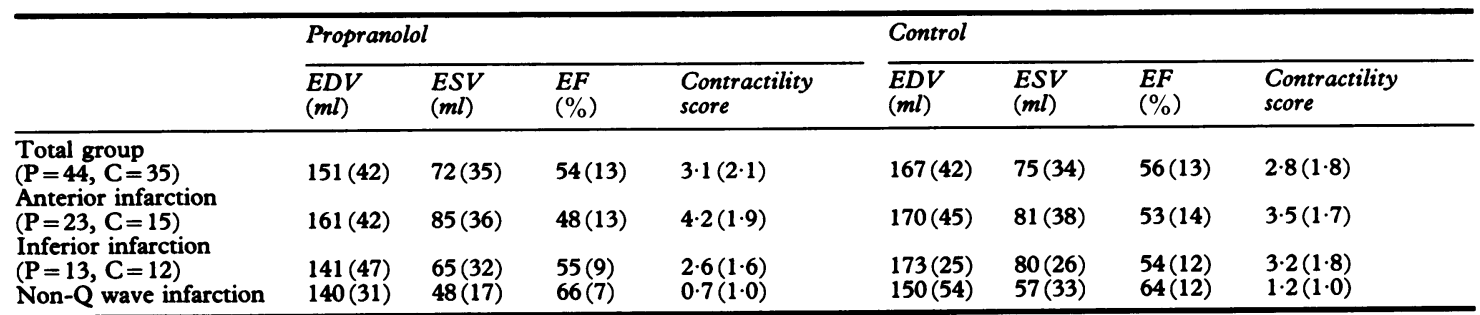

P, propranolol; C, control; EDV, end diastolic volume; ESV, end systolic volume; EF, ejection fraction. Values are mean (SD). 


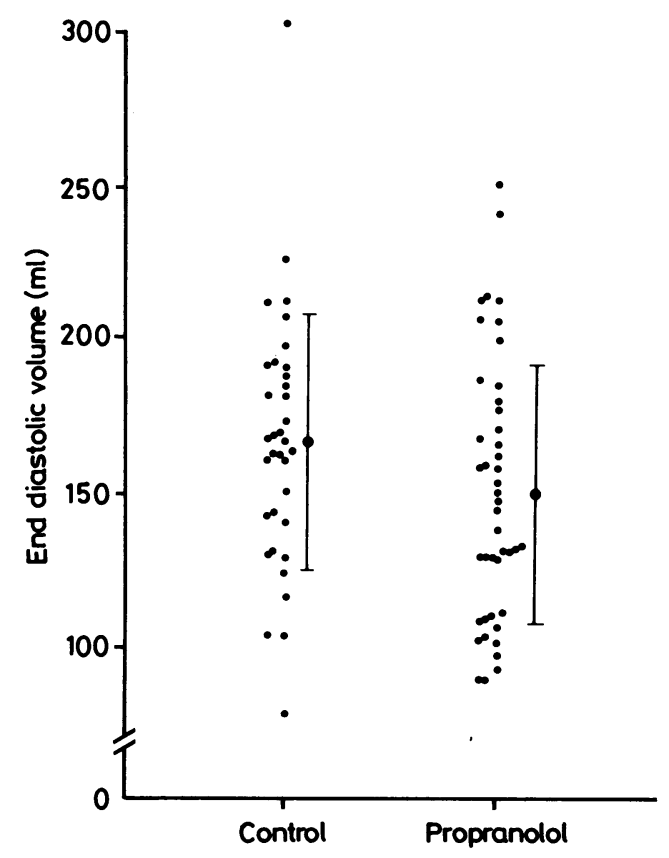

Fig. 3 End diastolic volumes of individual patients in control and propranolol groups. There is a non-significant trend to lower end diastolic volumes in the propranolol group $(2 p=0.08)$.

reached significance only with inferior $Q$ wave infarcts (141(47) vs 173(25) $\mathrm{ml}, \mathrm{p}=0.04)$. Despite early entry to the trial, when intervention may be of most benefit, $29 \%$ of all patients had abnormal $Q$ waves in the area of infarction on entry (Table 1). These patients might have been least likely to benefit from intervention, since most of the eventual infarct size was likely to have already been reached. Reanalysis after exclusion of these cases, however, showed no benefit in the propranolol group.

The mean coronary arteriographic score was similar in both groups (propranolol 9.0(2.5), control 8.4 $(2 \cdot 2)$ ). Arteriography showed complete occlusion of the infarct related coronary artery in $76 \%$ of patients (propranolol $79 \%$, control $74 \%$ ). The coronary score of an occluded infarct related artery is a measure of the volume of myocardium distal to the occlusion, and according to our scoring system when it is divided by 15 it estimates the proportion of the left ventricle which has lost its primary blood supply. The mean score of the infarct related coronary artery of the control group was 4.6 (31\% of the left ventricle), while that of the propranolol group was also 4.6, indicating that the volume of myocardium at risk from infarction was similar. Comparison of patients treated with propranolol or conventionally in whom incomplete occlusion of the infarct related artery was found at coronary angiography showed no significant improvement of ventricular function in the propranolol group.

\section{Discussion}

There was no apparent significant difference in exercise duration or the frequency of angina between propranolol and control groups. End systolic volume, ejection fraction, and subjective assessment of the severity of regional dysfunction were also not significantly different in these groups. There was a trend to lower end diastolic volumes in the propranolol group which approached statistical significance.

The similarity of the groups at entry is clearly important to any conclusions drawn about the value of this intervention. The propranolol group was significantly older with a higher percentage of patients having electrocardiographic ST elevation on entry $(p=0 \cdot 1)$ and completed anterior $Q$ wave infarction on discharge $(p=N S)$. The extent of coronary artery disease and the size of the occluded infarct related vascular bed are important determinants of infarct size and these variables were similar in the two groups. There was, however, a wide variance for each index of ventricular function in both groups that was due to spontaneous variation in infarct size. Given the variance in this study, a sample of 107 patients in each group would have been necessary to detect a difference in ejection fraction of $5 \%$ at a significance level of $2 p=0.05$ with a probability of $80 \%$. No improvement in mean ejection fraction was seen in the propranolol group, however, suggesting that a larger study is unlikely to show a clinically significant improvement in ventricular systolic function.

We believe that ours is the first study to examine adequately the effect on left ventricular function of early intervention with intravenous beta blockers. The effect on ventricular function after infarction of delayed intervention with acebutolol has been reported $^{11}$; no significant improvement in late ejection fraction or ventricular volumes was seen when intravenous acebutolol was given six to 24 hours after the onset of chest pain. This protocol, however, was designed to prevent infarct extension rather than to limit infarct size by early intervention. We reported the results of angiocardiography in $28 \mathrm{pa}-$ tients enrolled in an earlier trial of propranolol, ${ }^{10}$ but the limited number of patients that we studied may have been responsible for the failure to show improvement in left ventricular function with propranolol.

Experimental and clinical evidence strongly suggests, however, that infarct size is limited after intra- 
venous administration of beta blockers. Experimental evidence is based on reduction of the extent of infarction seen at necropsy, ${ }^{12-14}$ preservation of creatine kinase enzyme activity, ${ }^{15}$ and prevention of microvascular ${ }^{16}$ and mitochondrial ${ }^{17}$ injury. Creatine kinase release correlates strongly with anatomical infarct size measured at necropsy in patients who die from infarction, ${ }^{18-20}$ and it also correlates reasonably well with subjective assessment of myocardial function assessed by cineangiography after infarction ${ }^{8}$ and assessment of the percentage of abnormally contracting segments. ${ }^{21}$ We have previously shown a $20 \%-30 \%$ reduction in creatine kinase release when propranolol was given within four hours of the onset of chest pain, ${ }^{210}$ and this result has been confirmed in further trials that assessed the effect of other beta blockers. ${ }^{34} \mathrm{Im}$ portant variables such as the maximal duration of chest pain and the propranolol regimen used in this study were identical to those in our previous studies. The reduction in double product after intravenous and oral propranolol was also similar, and, although a measurement of creatine kinase release was not repeated in this study, there is no reason to expect a result dissimilar to our previous studies. Vectorcardiographic analysis also correlates with extent of infarction determined experimentally in baboons, ${ }^{22}$ and preservation of $Q R S$ vector has been reported with timolol. ${ }^{4}$

A conclusion from the evidence cited above is that limitation of infarct size by $20 \%-30 \%$ with early administration of beta blockers should lead to improvement in ventricular function. This hypothesis has not previously been tested and is not supported by our results. Experimental evidence, however, suggests that limitation of infarct size by $20 \%-30 \%$ would not necessarily lead to a parallel improvement in myocardial function. Hearse and Yellon have addressed the controversy about the border zone of infarction and have suggested that a significant border zone does not exist at the edge of the developing infarction, but rather lies in the transmural plane between subepicardium and subendocardium. ${ }^{23}$ Flow gradients in the transmural plane favouring the subepicardium occur after acute coronary artery ligation in $\operatorname{dogs}^{524}$ and it is the subepicardium which seems to be protected by treatment with propranolol. ${ }^{1215} \mathrm{~A}$ similar situation has been reported in man, ${ }^{25}$ where the relation of infarct size to the vascular bed at risk was the result of variation in the transmural extent of necrosis and not the result of variation in the lateral zone of viable muscle, which was consistently narrow.

Preservation of subepicardial myocardium may not contribute to regional function. Sonomicrometry in normal myocardium: of dogs has shown that the inner half of the myocardium contributes approximately $70 \%-80 \%$ of the overall wall thickening, ${ }^{2627}$ so that the subepicardial myocardium may not contribute greatly to total wall thickening. Ellis et al recently reported on the correlation of infarct size with myocardial contractile function in dogs during coronary artery reperfusion. ${ }^{28}$ Reduction by more than $40 \%$ of the transmural extent of infarction was necessary before there was a significant improvement in contractile function. Thus salvage of myocardium in the infarct zone to the degree seen with propranolol may not be sufficient to result in an improvement in ventricular systolic function.

It is conceivable, however, that preservation of subepicardium might splint the infarct zone and prevent infarct expansion. ${ }^{29}$ This could limit the increase in end diastolic volume, and this would accord with the trend which we found in the present study. None the less the functional sequelae at best appear to be small and we consider it unlikely that beta blocker therapy will significantly reduce mortality from cardiogenic shock or cardiac failure. Improved myocardial preservation may result from the combination of treatment with beta blockers and reperfusion, ${ }^{30}$ while maintaining the benefit of prevention of ventricular fibrillation. ${ }^{6}$

This study was supported by the Medical Research Council and the National Heart Foundation of New Zealand.

\section{References}

1 Maroko PR, Kjekshus JK, Sobel BE, et al. Factors influencing infarct size following experimental coronary artery occlusions. Circulation 1971; 43: 67-82.

2 Peter T, Norris RM, Clarke ED, et al. Reduction of enzyme levels by propranolol after acute myocardial infarction. Circulation 1978; 57: 1091-5.

3 Yusuf S, Sleight P, Rossi P, et al. Reduction in infarct size, arrhythmias and chest pain by early intravenous beta blockade in suspected acute myocardial infarction. Circulation 1983; 67 (suppl 1): 32-41.

4 The International Collaborative Study Group. Reduction of infarct size with the early use of timolol in acute myocardial infarction. $N$ Engl $\mathcal{F}$ Med 1984; 310: 9-15.

5 Reimer KA, Lowe JE, Rasmussen MM, Jennings RB. The wavefront phenomenon of ischemic cell death. I. Myocardial infarct size vs duration of coronary occlusion in dogs. Circulation 1977; 56: 786-94.

6 Norris RM, Barnaby PF, Brown MA, et al. Prevention of ventricular fibrillation during acute myocardial infarction by intravenous propranolol. Lancet 1984; ii: 883-6.

7 Whitlock RML, Bass NM. Left ventricular volume estimation by single plane right anterior oblique cineangiocardiography. Biological Engineering Society. Twentieth International Conference on Recent Advances in Biomedical Engineering Proceedings. 
1980: 177-8.

8 Sammel NL, Stuckey JG, Brandt PWT, Norris RM. Comparison of enzymic with cineangiocardiographic estimations of myocardial infarct size. Br Heart $\mathcal{F} 1980$; 43: 609-16.

9 Brandt PWT, Partridge JB, Wattie WJ. Coronary arteriography; method of presentation of the arteriogram report and a scoring system. Clin Radiol 1977; 28: 361-5.

10 Norris RM, Sammel NL, Clarke ED, Brandt PWT. Treatment of acute myocardial infarction with propranolol. Further studies on enzyme appearance and subsequent left ventricular function in treated and control patients with developing infarcts. Br Heart $\mathcal{F} 1980$; 43: 617-22.

11 Azancot I, Lorente P, Georgiopoulos G, et al. Effects of acebutolol on myocardial infarct extension: a randomized electrocardiographic, enzymatic and angiographic study. Circulation 1982; 66: 986-94.

12 Rasmussen MM, Reimer KA, Kloner RA, Jennings RB. Infarct size reduction by propranolol before and after coronary ligation in dogs. Circulation 1977; 56: 794-8.

13 Miura M, Thomas R, Ganz W, et al. The effect of delay in propranolol administration on reduction of myocardial infarct size after experimental coronary artery occlusion in dogs. Circulation 1979; 59: 1148-57.

14 Shatney $\mathrm{CH}$, MacCarter DJ, Lillehei RC. Effects of allopurinolol, propranolol and methylprednisolone on infarct size in experimental myocardial infarction. $A m \mathcal{F}$ Cardiol 1976; 37: 572-80.

15 Sammel NL, Norris RM, Hughes CF, Johnson RN, Ashton NG, Elliott RL. Severity of canine myocardial infarcts in relation to indices of oxygen demand: preservation of myocardial creatine kinase activity by vagal stimulation and propranolol. Cardiovasc Res 1983; 17: 50-60.

16 Kloner RA, Fishbein MC, Cotran RS, Braunwald E, Maroko PR. The effect of propranolol on microvascular injury in acute myocardial ischemia. Circulation 1977; 55: $872-80$.

17 Kloner RA, Fishbein MC, Braunwald E, Maroko PR. Effect of propranolol on mitochondrial morphology during acute myocardial ischemia. Am $\mathcal{F}$ Cardiol 1978; 41: 880-6.

18 Bleifeld W, Mathey D, Hanrath P, Buss H, Effert S. Infarct size estimated from serial serum creatine phosphokinase in relation to left ventricular hemodynamics.
Circulation 1977; 55: 303-11.

19 Grande P, Hansen BF, Christiansen C, Naestoft J. Estimation of acute myocardial infarct size in man by serum CK-MB measurements. Circulation 1982; 65: 756-64.

20 Reimer KA, Hackel DB, Ideker RE, et al. Comparison of enzymatic and anatomic estimates of myocardial infarct size in man [Abstract]. Clinical Research 1983; 31: $214 A$

21 Rogers WJ, McDaniel HG, Smith LR, Mantle JA, Russell RO Jr, Rackley CE. Correlation of angiographic estimates of myocardial infarct size and accumulated release of creatine kinase MB isoenzyme in man. Circulation 1977; 56: 199-205.

22 Wickline SA, McNamara JJ. Vectorcardiographic quantification of infarct size in baboons. Circulation 1978; 57: 910-20.

23 Hearse DJ, Yellon DM. The "border zone" in evolving myocardial infarction: controversy or confusion? $\mathrm{Am} \mathcal{F}$ Cardiol 1981; 47: 1321-34.

24 Vokonas PS, Malsky PM, Paul SJ, Robbins SL, Hood WB Jr. Radioautographic studies in experimental myocardial infarction: profiles of ischemic blood flow and quantification of infarct size in relation to magnitude of ischemic zone. Am $\mathcal{F}$ Cardiol 1978; 42: 67-75.

25 Lee JT, Ideker RE, Reimer KA. Myocardial infarct size and location in relation to the coronary vascular bed at risk in man. Circulation 1981; 64: 526-34.

26 Sabbah HN, Marzilli M, Stein PD. The relative role of subendocardium and subepicardium in left ventricular mechanics. Am f Physiol 1981; 240: H920-6.

27 Gallagher KP, Matsuzaki M, Kemper WS, Ross J Jr. Inner wall thickening during coronary stenosis in conscious dogs [Abstract]. Circulation 1983; 68 (suppl III): 156.

28 Ellis S, Wynne J, Henschke C, Sandor T, Kloner RA. Relation of myocardial salvage with coronary reperfusion to function at 14 days: importance of transmurality of infarction [Abstract]. $\mathcal{f} \mathrm{Am}$ Coll Cardiol 1984; 3: 523.

29 Erlebacher JA, Weiss JL, Eaton LW, Kallman C, Weisfeldt ML, Bulkley BH. Late effects of acute infarct dilation on heart size: a two dimensional echocardiographic study. Am $\mathcal{f}$ Cardiol 1982; 49: 1120-6.

30 Reynolds RD, Burmeister WE, Gotczynski RJ, Dickerson DD, Mathews MP, Lee RJ. Effect of propranolol on myocardial infarct size with and without coronary artery reperfusion in the dog. Cardiovasc Res 1981; 14: 411-20. 